\title{
In cholestatic hepatic dysfunction, also consider the kid- neys and the heart: A probable case of Stauffer syndrome in renal leiomyosarcoma with cava-atrial extension
}

\author{
Ruth Jones, Les Ala
}

\begin{abstract}
Introduction: Abnormal liver function tests (LFTs) are a common reason for referral to hospital although in some cases, no obvious hepatic pathology is found. Yet, they can indicate other disease processes not immediately obvious. A rare cause of cholestatic hepatic dysfunction is the paraneoplastic manifestation of malignancy. Case Report: Herein, we report a case referred with anicteric cholestatic hepatic dysfunction that was found to have a renal leiomyosarcoma with inferior vena cava (IVC) and right atrium extension. Conclusion: The abnormal LFTs were thought to be a paraneoplastic manifestation of the tumor as these were improving following surgical treatment.
\end{abstract}

Keywords: Renal leiomyosarcoma, Stauffer syndrome, Inferior vena cava (IVC) right atrial tumor extension, IVC obstruction

$* * * * * * * * *$

Jones R, Ala L. In cholestatic hepatic dysfunction, also consider the kidneys and the heart: A probable case of Stauffer syndrome in renal leiomyosarcoma with cavaatrial extension. International Journal of Case Reports and Images 2013;4(11):619-622.

Ruth Jones ${ }^{1}$, Les Ala ${ }^{2}$

Affiliations: 'BSc, Highly Specialist Cardiac Physiologist, Royal Glamorgan Hospital, LLantrisant, South Wales CF72 8XR, United Kingdom; ${ }^{2} \mathrm{MRCP}(\mathrm{UK})$, Consultant Acute Physician, Royal Glamorgan Hospital, LLantrisant, South Wales CF72 8XR, United Kingdom.

Corresponding Author: Dr. Les Ala, 37 Thriepland Drive, Cardiff, Vale of Glamorgan, Wales, CF14 4PY; Ph: +44 (0)1443 443 443; Email: leslie.ala@wales.nhs.uk

Received: 01 September 2012

Accepted: 26 July 2013

Published: 01 November 2013
doi:10.5348/ijcri-2013-11-394-CR-8

\section{INTRODUCTION}

This is a case of a primary renal leiomyosarcoma presenting with hepatic dysfunction and features of intraluminal tumor extension. Following surgical treatment, the patient started to experience improvement in her symptoms as well as her liver function. It highlights the need to consider extra-hepatic causes of hepatic dysfunction including possible paraneoplastic manifestations of malignancies.

\section{CASE REPORT}

Clinical features: A 61-year-old female was referred to our ambulatory care unit with a three-month history of worsening dyspnea on exertion. The referral was prompted by the discovery of abnormal liver function tests (LFTs) by her general practitioner. She had a dry cough and ankle swelling, but denied any other respiratory or cardiac symptoms. She did have ongoing right sided flank pain, and pain 'under her ribs' for last two months, described as constant without pleurisy or radiation. On systemic review, she denied weight loss, bowel or urinary symptoms, specifically frank hematuria, but complained of lethargy and intermittent pyrexia over the previous month.

Previously, she had had an oophorectomy for a benign teratoma, and a deep venous thrombosis 10 years before. She denied previous liver or renal problems. She was not on regular medication, did not smoke nor drunk alcohol. Physical examination revealed a slightly pale but comfortable lady with no icterus, clubbing, or obvious lymphadenopathy. Cardiovascular and respiratory examination were normal (blood pressure $135 / 85 \mathrm{mmHg}$ ) but there were prominent ' $a$ ' waves in her jugular veins. Her superficial abdominal veins were distended with flow 
directed upwards towards the head on re-filling. As well as hepatomegaly ( $4 \mathrm{~cm}$ below the costal margin), she had an indistinct mass in the right flank. Her swollen ankles were mildly pitied.

Investigations: Blood tests showed a normocytic anemia, cholestatic hepatic dysfunction and raised inflammatory markers (Table 1). Thyroid function tests, electrolytes and hematinic profile were normal. Subsequent viral hepatitis and liver autoantibodies screen were negative. Urinalysis showed microscopic hematuria $(++++)$ and proteinuria $(++)$. Her electrocardiogram showed a sinus tachycardia (106 beats per minute).

A chest X-ray showed an elevated right hemidiaphragm, a new finding as of 5 years previously, but clear lung fields (Figure 1). An ultrasound scan revealed a large right renal mass with a suspicion of IVC tumor extension; the liver was enlarged but there was no obvious metastatic liver disease or biliary tree dilatation.

Following contrast computed tomography (CT) scan of her thorax and abdomen, the large right renal tumor was confirmed, and was seen to extend into the renal vein, IVC and RA (Figure 2). There was no evidence of pulmonary embolism and no liver metastasis but there was a small amount of abdominal free fluid and small bilateral pleural effusion.

On transthoracic echo, a large tumor occupying the entire right atrium was noted and was seen to extend into the inferior vena cava (IVC). There was no tricuspid valve involvement and all other echo findings were within normal parameters (Figure 3).

Table 1: Blood test results at presentation and two months after surgery.

\begin{tabular}{lccc}
\hline Parameter & $\begin{array}{c}\text { At } \\
\text { presentation }\end{array}$ & $\begin{array}{c}\text { 2 } \\
\text { months } \\
\text { after } \\
\text { surgery }\end{array}$ & $\begin{array}{c}\text { Normal } \\
\text { Range and } \\
\text { units }\end{array}$ \\
\hline $\begin{array}{l}\text { Alkaline } \\
\text { phosphotase }\end{array}$ & 211 & 182 & $30-130 \mathrm{U} / \mathrm{L}$ \\
$\begin{array}{l}\text { Gama-glutamyl } \\
\text { transferase }\end{array}$ & 201 & 117 & $12-43 \mathrm{U} / \mathrm{L}$ \\
$\begin{array}{l}\text { Total bilirubin } \\
\begin{array}{l}\text { Alanine } \\
\text { transaminase }\end{array}\end{array}$ & 19 & 12 & $0-21 \mathrm{umol} / \mathrm{L}$ \\
$\begin{array}{l}\text { C-reactive protein } \\
\text { Ferritin }\end{array}$ & 170 & 28 & $0-52 \mathrm{U} / \mathrm{L}$ \\
$\begin{array}{l}\text { Erythrocyte } \\
\text { sedimentation } \\
\text { rate }\end{array}$ & 344 & 270 & $15-300 \mathrm{ug} / \mathrm{L}$ \\
$\begin{array}{l}\text { Hemoglobin } \\
\text { Prothrombin }\end{array}$ & N/A & 83 & $1-20 \mathrm{~mm} / \mathrm{hr}$ \\
time & 10.8 & 10.6 & $11.5-16.5 \mathrm{~g} / \mathrm{dL}$ \\
\hline & 16 & On & $11-14.5 \mathrm{~s}$ \\
\hline & & warfarin & \\
\hline
\end{tabular}

Management: Subsequently, the patient was, transferred to a tertiary center under the joint care of the urological and cardiothoracic surgical team, where she had a radical right nephrectomy, atrial and caval tumor thrombectomy and IVC replacement with Dacron graft and femoral vein. After a prolonged post-surgery stay in the intensive care unit, she made a good recover and on

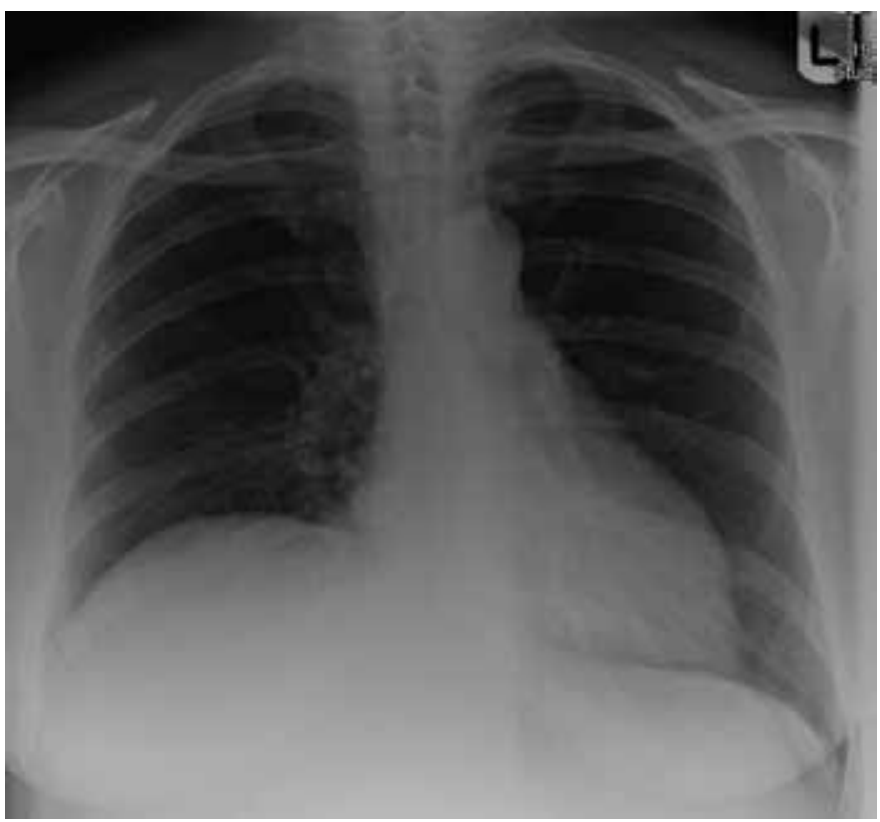

Figure 1: Chest X-ray showing elevated right hemi-diaphragm.

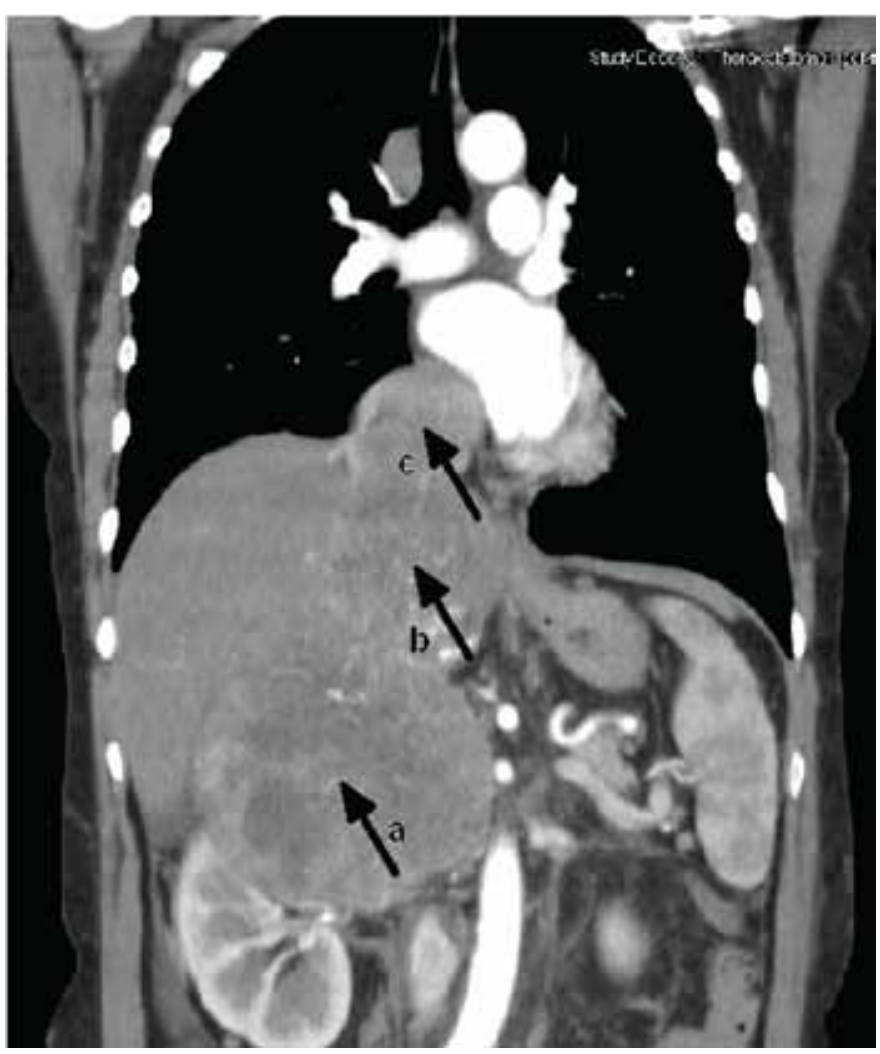

Figure 2: Contrast Computed tomography scan showing renal tumor (arrow a) with extension into inferior vena cava (arrow b) and into right atrium (arrow c). 
follow-up two months after the surgery, she remained well with marked improvement in her symptoms.

The tumor was confirmed to be a high grade renal leiomyosarcoma. Further adjuvant treatment is currently being discussed with the oncologists. She remains on longterm warfarin for venous thrombo-embolic prophylaxis.

Following surgical treatment and two months after surgery, her LFTs appear to be improving (Table 1) although they have not as yet returned to normal. A postoperative prothrombin time was not measured as she had been put on warfarin during this period. A post-surgical echo showed a normal sized right atrium with no residual mass in the right atrium or the IVC (Figure 3).
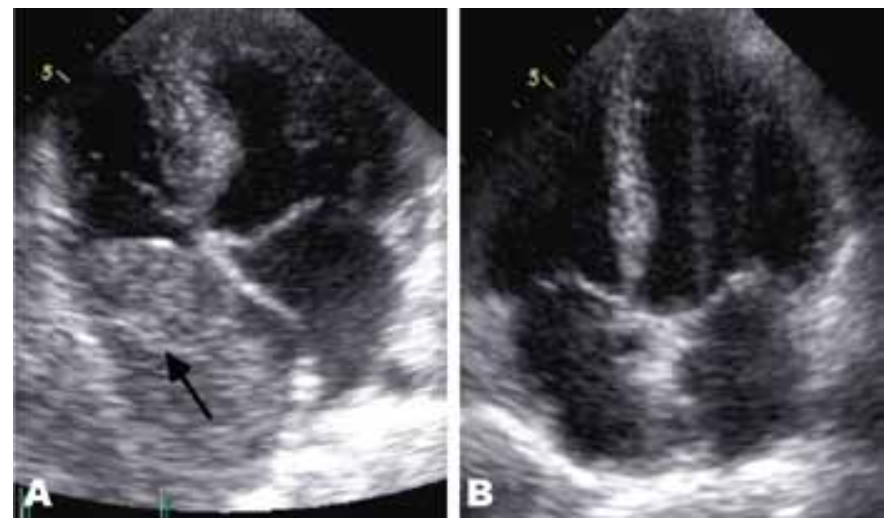

Figure 3: (A) Echo showing right atrium mass before surgery (arrow, left), (B) Echo showing normal right atrium after surgery (right).

\section{DISCUSSION}

Primary renal leiomyosarcoma is extremely rare, accounting for only $0.5^{-1 \%}$ of all renal invasive tumors [1]. They may arise from the smooth muscle fibers of renal parenchyma, renal capsule, renal pelvis, or renal vessels [2]. These tumors often mimic renal cell carcinoma (RCC) in their presentation namely flank pain, palpable mass, and hematuria all of which are indicators of extensive local disease [1].

Intraluminal extension of the tumor from the kidney into the IVC and beyond is uncommon although some cases have been reported previously [3, 4]. Inferior vena cava involvement may produce lower extremity edema, ascites, hepatic dysfunction and pulmonary emboli.

Other features are more inconspicuous at presentation, particularly the paraneoplastic manifestations. This patient was referred with abnormal LFTs indicating a cholestatic hepatic dysfunction but in the absence of hepatic vein thrombosis, liver metastasis or biliary tree obstruction, such a hepatic profile might indicate Stauffer syndrome, a rare paraneoplastic manifestation of leiomyosarcoma [5].

Stauffer syndrome is well described in renal cell carcinoma but it has been reported in other malignancies such as bronchial carcinoma, prostate adenocarcinoma and there was one previously reported case in literature of Stauffer syndrome in leiomyosarcoma [5-8]. First described in 1961, Stauffer syndrome is characterized by an elevated alkaline phosphatase, gammaglutamyltransferase (GGT), erythrocyte sedimentation rate (ESR), a prolongation of prothrombin time and hepatosplenomegaly. Histological examination of the liver shows non-specific inflammatory infiltrates [9]. The abnormal blood tests return to normal after surgical resection of the tumor but they reappear if the tumor recurs. The pathogenesis of this paraneoplastic syndrome is not fully understood but it is thought to be related to the release of pro-inflammatory cytokines such as interleukin-6 (IL-6) [10].

Although she had the classic triad of a renal tumor at presentation (flank pain, hematuria and abdominal mass), she also had features of IVC obstruction and possible cardiopulmonary complications. Tumor fragments could even embolize so given her dyspnea and features of possible IVC thrombotic obstruction, pulmonary embolism was in the differential diagnoses. However, with an elevated right hemi-diaphragm on CXR, a mass in the right flank and abnormal LFTs, we felt an ultrasound of abdomen was also warranted at that stage, and this identified a renal mass, confirmed IVC obstruction and excluded liver metastasis. The subsequent contrast CT thorax and abdomen showed the extent of the tumor and excluded pulmonary embolism.

The extension of the leiomyosarcoma into the right atrium may obstruct blood flow and cause signs and symptoms of right heart failure such as fatigue, peripheral edema, hepatomegaly and ascites. This patient did have some of these features but surprisingly, on echocardiography, her cardiac function was not compromised despite the tumor occupying the entire right atrium. The small amount of ascites and her lower limb swelling were therefore most likely due to IVC obstruction rather than right heart dysfunction.

The final diagnosis was only possible from histological examination as the tumor was indistinguishable from an $\mathrm{RCC}$ on the radiological images and at surgery.

\section{CONCLUSION}

Although renal leiomyosarcoma is extremely rare, it can mimic renal cell carcinoma at presentation. In this patient with a renal leiomyosarcoma, the improving trend of the cholestatic hepatic profile after surgery indicates that she probably had an associated Stauffer syndrome although she would require a longer follow-up period to ensure the liver function tests have returned to normal.

Nevertheless, her case illustrates the wide spectrum of manifestations of renal tumors and their complications, including inferior vena cava and right atrium extension and associated paraneoplastic syndromes. 
In such patients, as well abdominal and thoracic radiological imaging, an echocardiogram is also required to exclude tumor embolus and RA mass, especially if they present with dyspnea, features of possible right heart dysfunction or of pulmonary embolism.

$* * * * * * * * *$

\section{Author Contributions}

Ruth Jones - Acquisition of data, Analysis and interpretation of data, Performed echocardiography, Critical revision of the article and helped to write the first draft, Final approval of the version to be published

Les Ala - Conception and design, Acquisition of data, Analysis and interpretation of data, Drafting the article, Final approval of the version to be published

\section{Guarantor}

The corresponding author is the guarantor of submission.

\section{Conflict of Interest}

Authors declare no conflict of interest.

\section{Copyright}

(C) Ruth Jones et al. 2013; This article is distributed under the terms of Creative Commons attribution 3.0 License which permits unrestricted use, distribution and reproduction in any means provided the original authors and original publisher are properly credited. (Please see www.ijcasereportsandimages.com/copyright-policy.php for more information.)

\section{REFERENCES}

1. Dhawan S, Chopra P, Dhawan S. Primary renal leiomyosarcoma: A diagnostic challenge. Uro Ann 2012;4(1):48-50.

2. Deyrup AT, Montgomery E, Fisher C. Leiomyosarcoma of the kidney: A clinicopathologic study. Am J Surg Pathol 2004;28(2):178-2.

3. Zigman A, Shen I. Clear cell sacoma of the kidney with cavo-atrial tumour thrombus: complete resection in a child. J Pediatric Surg 2006;41(8):1464-6.

4. Dufour B, Choquenet C, Nacash G. [Primary leiomyosarcoma of the right renal vein with extension into the inferior vena cava]. J Urol (Paris) 1982;88(8):561-5.

5. Fraisse TC, Damigny A, di Castri A, de Wazieres B, Fourcade J. [Leiomyosarcoma and Stauffer syndrome]. Rev Med Interne 2001;22(11):1116-8.

6. Stauffer MH. Nephrogenous hepatosplenomegaly. Gastroenetrology 1961;40:694.

7. Saintigny P, Spano JP, Tcherakian F, Pailler MC, Bream JL. [Non-metastatic intrahepatic cholestasis associated with bronchial adenocarcinoma]. Ann Med Interne (Paris) 2003;154 (3):171-5.

8. Karakolios A, Kasapis C, Kallinikidis T, Kalpidis P, Grigoriadis N. Cholestatic jaundice as a paraneoplastic manifestation of prostate adenocarcinoma. Clin Gastroenterol Hepatol 2003;1(6):480-3.

9. Aoyagi T, Mori I, Ueyama Y, Tamaoki N. Sinusoidal dilatation of the liver as a paraneoplastic manifestation of renal cell carcinoma. Hum Pathol 1989;20(12):1193-7.

10. Blay JY, Rossi JF, Wijdenes J, et al. Role of interleukin-6 in the paraneoplastic inflammatory syndrome associated with renal-cell carcinoma. Int J Cancer 1997;72(3):424-30.
Access full text article on other devices

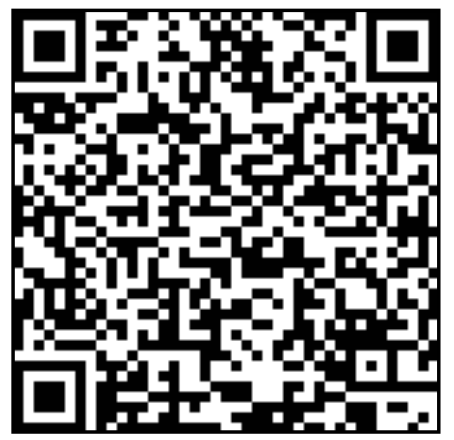

Access PDF of article on other devices

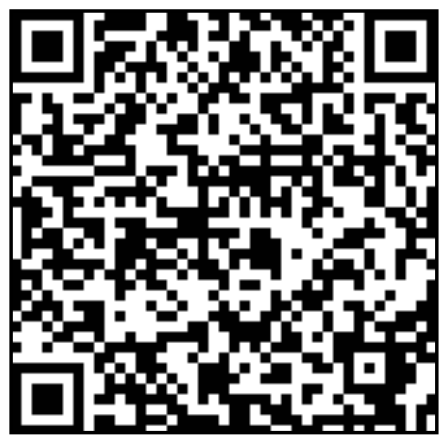

